\title{
Investigating teams of neuro-typical and neuro- atypical students learning together using COGLE: A multi case study.
}

\author{
Manish Malik \\ School of Energy and Electronics \\ Engineering, \\ University of Portsmouth, \\ Portsmouth, England, United Kingdom. \\ https://orcid.org/0000-0001-8233-6357
}

\author{
Julie-Ann Sime \\ Centre for Technology Enhanced \\ Learning, \\ Educational Research Department \\ Lancaster University \\ Lancaster, England, United Kingdome \\ https://orcid.org/0000-0002-3964-0684
}

\begin{abstract}
This Work in Progress Research paper aims to contribute to theories relevant to trust, self-efficacy and team effectiveness in engineering student teams. Self-efficacy and trust in teammates are both crucial for team effectiveness. Borrego et al. in a review on team effectiveness within engineering education have highlighted the scarcity of research on psychological constructs, such as trust. This work was inspired by their call for more research that connects engineering education research with the industrial and organisational psychology literature to improve engineering education practice and the outcomes relating to team working. Team working depends on social and communication skills of individual teammates. However, collaborative teams can experience socio-communication challenges. These can be even more pronounced in neuro-atypical (NT) students. With an increasing number of students, hidden or diagnosed, who are neurologically atypical (NAT) within engineering courses investigating ways to support development of trust and selfefficacy has become even more important. Using two real-world case studies, the efficacy of the Computer Orchestrated Group Learning Environment (COGLE), a novel software intervention that supports the development of trust and self-efficacy of individuals in teams of neuro-typical and neuro-atypical students, is investigated using qualitative and quantitative methods. In particular to answer the two research questions: 1. How does the use of COGLE affect the self-efficacy of NT and NAT engineering students learning together? 2. How does the use of COGLE affect the development of trust between a team of NT and NAT engineering students learning together? The case studies show how COGLE can be used within two pedagogical approaches: Flipped Classroom and Project Based Learning, which are commonly used in engineering education. The learning gain data and related effect sizes from both cases show that COGLE was successful in enhancing self-efficacy in all students. Furthermore, both cases show three very interesting results relating to trust: firstly, the teammates developed trust in each other in just 4 two-hour sessions; secondly, the students, including the neuro-atypical students, were able to correct their trust due to varied interactions enabled by COGLE; and finally, as trust and self-efficacy was enhanced before students were asked to work together on a collaborative activity, it helped both neuro-typical and neuroatypical students to be fully involved in team work, thereby improving the team's effectiveness. The implication for practice is that COGLE can be used to effectively prepare all students for as shown by learning gain and increased levels of trust and enhance team effectiveness.
\end{abstract}

Keywords-ASD, ADHD, Neurologically atypical and typical, Computer supported collaborative learning (CSCL) at computer, Trust, Self-efficacy, Team effectiveness.

\section{INTRODUCTION}

This paper presents research and initial findings from a case study research with literal replication that investigates the development of trust within teams of neurologically typical and also mixed teams of neurologically typical (NT) and neurologically atypical (NAT) students. Such a mix is getting increasingly more relevant to engineering education. NAT refers to those with Autistic Spectrum disorder (ASD) and Attention Deficit Hyperactivity Disorder (ADHD). This research uses an in-house developed software, Computer Orchestrated Group Learning Environment (COGLE), see section III A, which orchestrates the interactions between small teams of 3-4, NT and NAT students learning together in the same physical space without the presence of an academic. This paper is part of a larger research project in which interrelations between psychological constructs such as trust and conflict are being studied in collaborative approaches such as Project Based Learning (PjBL) and Flipped Classroom (FC), commonly used to teach engineering students and across higher education institutions.

\section{BACKGROUND}

\section{A. Collaborative approaches within Engineering Education}

The use of collaborative settings within engineering programmes is both desirable and gaining popularity. Approaches like $\mathrm{PjBL}$ and $\mathrm{FC}$ are just two such collaborative approaches being used by practitioners across the engineering education sector [1-6]. It is a response to the increasing demands from industry and professional, statutory and regulatory bodies for an increased focus on graduate skills in particular team working skills [3-5]. Traditionally, engineering education programmes have been too focussed on technical knowledge, however, this has been changing recently. Furthermore, collaborative approaches in engineering education have been shown to have a greater effect size $(\mathrm{d}=0.25)$ than individualistic approaches when it comes to acquiring technical knowledge and learning [7].

\section{$B$. Challenges relating to collaborative approaches}

Research highlights some challenges with the use of collaborative approaches within engineering education [8-11]. For examples, in FC settings a big concern is that students do not adequately prepare and come to class, which poses a threat to in class collaborative activities [8-9]. Likewise, PjBL tends to be resource intensive and faces internal criticisms and decreasing support within engineering schools across the sector [10-11]. NAT students face socio-communication challenges, which may affect their success in collaborative activities. Increased diagnose and number of NAT students in engineering programmes has further implications on the 
support provision for such students [11-12]. Actually, the challenges faced during team working and collaboration are not just limited to NAT students, many NT students also find learning and developing team working skills quite challenging [11].

\section{Rationale for doing this work}

Presentations of these challenges are seen in the presence of effects such as social loafing, cliques and ineffective teams widely mentioned in education literature [13-15]. Research shows that NAT students are more likely to prefer engineering and technology courses when making decisions on which field to choose [16]. Small teams of 3-5 students are commonly used within engineering education and with the increase in NAT diagnosis rate and students entering higher education [17-19], this makes it important that we understand how teams, mixed NT and NAT students or otherwise can be supported and be more effective.

Another reason why engineering education researchers should be interested in team effectiveness and in particular in the relevant psychological constructs is that there are very few studies within engineering education research that do so [20].

\section{MethodOLOGY}

This case study research with literal replication investigates trust and knowledge acquisition through the use of COGLE with two different cohorts studying a foundation degree in engineering and electronic engineering degree pathways. This section describes, the use of COGLE, the theoretical framework that guides it, the research design and the measurement instruments used.

\section{A. What is COGLE?}

COGLE is a support and orchestration tool that encourages a group-wide mastery goal via balanced and frequent interactions, between all teammates that are learning together in a shared physical space. COGLE scripts prompt students to engage in repeated interactions leading to the mastery of concept, which eventually helps transfer co and socially shared regulation of learning scripts. COGLE runs within a web browser and plays videos hosted anywhere on the web, for example YouTube ${ }^{\circledR}$. COGLE orchestrates, through its scripts, small groups of students who watch together the selected short videos followed by answering individually and synchronously a series of questions correctly. The questions repeat until the entire group achieves group-wide mastery of the content. The questions are carefully designed to encourage discussions between students and trigger cognitive conflicts. During each session, students are paired several times to carry out peer instruction with those who get the questions wrong and or to resolve the cognitive conflicts. The goal is to achieve group-wide mastery, which is met when all students in a team get 10 questions correct in a row. Anyone making a mistake resets this target and the group must start again. COGLE is able to identify mistakes that are prevalent within the group, thanks to the careful question design and plays a remedial video based on the most prevalent mistake in a team. Throughout these interactions, COGLE scripts prompt users to work together collaboratively and promote a cooperative environment.

\section{B. Theoretical Framework}

Mazur's Peer Instruction has been shown to encourage students to learn from each other [21-22]. The COGLE platform orchestrates grouping of learners in a random and inclusive way. Quiet or vociferous, no one is left out. This ensures turn taking is easy and all students including NAT get a chance to take part effectively in the group discussions. The concept of mastering content individually before moving on [23-24], is extended here into the social, as group-wide mastery to ensure all learners in a group achieve greater learning gains and therefore greater self-efficacy.

Trust itself is a multi-faceted construct and various contested models of trust exist in the literature [25]. This research focuses on three antecedents of trust namely affective trust, cognitive trust and conative trust. Readers are pointed to [2528] for a fuller definitions of these as used within this research. ASD students can sometimes miss the necessary social cues needed in correctly estimating when to trust other individuals [29]. This may also affect their turn taking ability, making others in the team trust them less. Therefore, looking at NAT students and how they develop trust in others within COGLE and how others develop trust in them, can help understand how best to support such students. The development of trust is crucial amongst all team mates for a team to be effective. We were therefore interested in two research questions stated below:

RQ1-How does the use of COGLE affect the self-efficacy of NT and NAT engineering students learning together?

$R Q 2$ - How does the use of COGLE affect the development of trust between a team of NT and NAT engineering students learning together?

\section{Research Design}

Two modules, one from level 3 (foundation year) and one from level 4 of the BEng Electronic Engineering course were chosen for this study. The module coordinator reviewed all the content and confirmed that the two will provide the necessary levels of similarities and differences that were needed in this research. The two modules had an introductory purpose to two different cohorts and the BEng module additionally covered advanced topics in electronic engineering.

A total of 19 students joined the study, 9 from level 3 foundation course in Engineering and Technology and 10 from the BEng Electronic Engineering course. However, 3 level 3 students did not complete the study, as one of their teammates, an international student, left without giving any explanation. The remaining 6 level 3 students were randomly put into teams of 3 each, within the FC arm of the study. One level 3 student self-declared themselves as autistic. The remaining 10 level 4 students joined the $\mathrm{PjBL}$ arm and were put in random teams of 3 or 4 students. One level 4 student had been diagnosed with autism (comorbid with ADHD) and another student had been diagnosed with ADHD. In the end, 16 students completed the study.

Students on the FC arm of the study learned together in their designated teams for 4 two-hour sessions prior to attempting a two hour FC collaborative design challenge. In their designated teams, students on the PjBL arm, did the same 4 two-hour sessions and in addition 3 further two-hour sessions ( 7 sessions in total) to master the content needed for the PjBL task. The FC task involved designing a bass and treble filter circuit to be used as input to a head-phone amplifier. The PjBL task was more complex where the students were required to design both the filter circuits as well as the headphone amplifier within the same two-hour session. 
Students in the PjBL arm of the study learnt how to design amplifiers in addition to filter design. The two arms of the study, thus formed part of a literal replication multi-case study [30]. This research adopts a case study methodology whereby each arm of the study is a case. The strength of this approach is that each case is selected, on the basis of theory to predict similar results, which adds to the strength of the findings.

\section{Learning Gain and Self-efficacy}

We were interested to measure learning gain, as it indicates the impact of COGLE on student learning, which is an important factor linked to self-efficacy. In order to measure the technical knowledge the NT and NAT students were able to acquire as a result of taking part in COGLE sessions, they were assessed both before the first (Pretest) and after the last (Posttest) COGLE session in each arm of the study by administering the same test before and after the COGLE sessions. This test, consisting of questions that assess knowledge acquisition on topics taught by videos in COGLE, had been tested within a pilot prior to the study. Normalised learning gains were calculated for both of the cases with the formula shown in (1).

$$
\text { Normalised Learning gain }=\frac{\text { Posttest-Pretest }}{100-\text { Pretest }}
$$

Additionally, statistical methods like t-tests and effect size were used, as the data collected was normally distributed, to test the hypotheses as follows:

$H_{0}$ - There is no statistically significant difference between a student's scores before and after the use of COGLE.

$H_{1}$ - There is a statistically significant difference between a student's scores before and after the use of COGLE.

If learning together with COGLE results in $\mathrm{H}_{1}$ being supported, it means that COGLE has helped improve student self-efficacy, which will be explored further in the interview data for triangulation.

\section{E. Measuring Trust}

Trust is conceptualised formatively as something that leads to trust and reflectively as a future intention to engage in something (risk related) [26]. In this study, we see trust as formative, based on Mayer et al.'s work [26], and dependent on three dimensions, namely affective ("my teammates help me when I need it.") and cognitive ("my teammates are knowledgeable in the topic area we are studying together.") [27] and conative ("my teammates can be counted on.") [28]. A survey, adapted from Mayer et al.'s work on trustworthiness, was used to measure the three facets leading to trust beforehand, after 4 COGLE sessions and also after 7 COGLE session within PjBL arm. Trust data was also collected before and after the FC or PjBL activity.

As there is no agreement if trust should be measured quantitatively or qualitatively, we also collected qualitative data at the end of the study through an hour long interview to understand the antecedents of trust. The interviews were transcribed verbatim by a professional transcriber and qualitatively analysed for themes. This mixed methods approach used within this study fits well with being an engineer as a pragmatic approach is commonly used by engineers.

\section{RESULTS}

Firstly, the learning gain was computed for each case and also the effect size was calculated.

\section{A. Learning Gain and Self-efficacy}

1) The Flipped Classroom Case

A Kolmogorov test of normality was performed on the pre and the post test data from FC case $(n=6)$. The $p$-value was $0.89036(>0.05)$ for the posttest score and p-value for the pretest was $0.91253(>0.05)$. This means that the data does not differ significantly from that which is normally distributed and therefore a t-test was carried out with a t value $=5.416328$ and a $\mathrm{p}$-value $=0.0029$, meaning the result is significant $(\mathrm{p}<0.01)$ and the null hypothesis is rejected. This equates to a large effect size of 1.7803 with confidence interval $(0.43,3.11)$.

\section{2) The Project Based Learning Case}

Likewise, for the PjBL case $(n=10)$, Kolmogorov test of normality was also performed on the pre and the posttest data. The p-value was $0.63674(>0.05)$ for the post test score and pvalue for the pretest was $0.64631(>0.05)$. This means that the data does not differ significantly from that which is normally distributed and therefore a t-test was carried out with a t value $=9.697417$ and a $\mathrm{p}$-value $=0.00001$, meaning the result is significant $(\mathrm{p}<0.01)$ and the null hypothesis is rejected. This equates to a large effect size of 3.369 with confidence interval of $(2.00,4.724)$.

In both cases, the learning gain results reflect the usefulness of the group-wide mastery approach used when preparing the content within COGLE. This means that the student's self-efficacy prior to going into the collaborative tasks (FC or PjBL) was indeed enhanced.

\section{B. Trust in teammates}

\section{1) The Flipped Classroom Case}

In a short period of just 4 two hour COGLE sessions, the survey results show that trust developed within teams and was more widespread for all three facets of trust (affective $n=6$, cognitive $n=5$ and conative $n=6$ ) compared to the start of the study (affective $n=5$, cognitive $n=2$ and conative $n=3$ ). Moreover, this measurement was found to be stable when measured just before the start of the FC activity, adding to the reliability of the survey. Another interesting finding from the survey results was that the student who self-declared as autistic was able to update the cognitive trust in their team based on the interactions within COGLE.

The interview data is still being analysed, although an interesting initial finding reveals the positive levels of trust the other teammates have in each other including the student with autism as shown in the quote below:

"I felt that...Ummmm. .. everyone went using the system first everyone felt that they had a really good grounding in the subject area that everyone is Working on in the project. I worked on the values of the resistors capacitors in the circuit and then Someone else was searching another person in our team was researching....like the high pass and low pass filters and then another person was Working out how the circuit would work and ... everyone work together." (Teammate of autistic student)

Thanks to the many interactions orchestrated by COGLE involving all students in this team, this indeed is an important result, as the student with autism became fully part of the team right till the end of the study and was supported by their team 
mates fully during the un-orchestrated final FC session where they worked together and designed the two filter circuits.

\section{2) The Project Based Learning Case}

Similarly, after a short period of just 4 two hour COGLE sessions, the survey results show that trust developed within the team and was more widespread for all three facets of trust (affective $n=9$, cognitive $n=9$ and conative $n=9$ ) compared to the start of the study (affective $n=6$, cognitive $n=6$ and conative $n=4$ ). Moreover, this measurement was found to be stable when measured just before the start of the PjBL activity (affective $n=10$, cognitive $n=10$ and conative $n=9$ ). There was an additional measurement in this case, one after 7 COGLE sessions. Trust levels were still widespread (affective $n=10$, cognitive $n=8$ and conative $n=7$ ) then. The interesting finding of the FC case was also repeated here, as the student with autism was able to update the cognitive trust in their team based on the interactions within COGLE. The student with ADHD was also able to improve and revise their trust levels based on the interactions that COGLE orchestrated.

The interview data confirms the important finding related to the positive level of trust that other members of the team had in all students, including the one with autism in this case too.

"It [COGLE] just... made it easier for us to talk to each other after like different tasks... make, make everyone on the same level and then carry on ... and I kept on getting it wrong...So, it would just be Giles or Harry, depending on whoever like [knows the topic will explain it to me]." (Teammate of autistic student)

Going into the task, the team mates had full trust in each other as show in the trust survey results.

\section{DisCUSSION AND CONCLUSION}

The two cases produce very similar outcomes, both in terms of learning gain results and trust in team mates, including those who are NAT. This adds strength to the findings of this study as we used a replication logic. Developing trust within teams within just 4 two-hour sessions is an impressive result as to the best of our knowledge no other study has been able to show the same. Interview data analysis is underway to find evidence for backing the decision to use learning gain data as a proxy for self-efficacy. The fact that there were ASD and ADHD students working in mixed teams of NT and NAT students adds to the significance of the work. The students came to the FC and PjBL activities with an enhanced team feeling and greater self-efficacy. They worked together as one team and all teams managed to complete the set tasks and score above $70 \%$ in most cases.

COGLE provide benefits for students and staff. After an initial investment in time to create video content and questions, COGLE can be deployed any number of times for any number of teams as permitted by the physical space. Using COGLE for FC preparation does change what may be commonly understood as the Flipped Classroom approach. Iinstead of expecting students to learn individually at home, students can attend preparatory sessions, where minimal supervision and no teaching is needed as this is orchestrated by COGLE instead of an academic. We call these sessions as Software Assisted Learning Together (SALT) sessions. During the FC activity academics can then orchestrate collaborative, active learning tasks based on content mastery within COGLE sessions. Likewise, for PjBL the students can learn together with minimal resources before attending their $\mathrm{PjBL}$ lab sessions and team meetings. This is where academics can provide facilitation and guidance on students' project work. Combining COGLE and an academic's work in this way can impact the student experience positively in the ways highlighted in this research for many engineering disciplines and beyond.

This work presented the evaluation of student performance in collaborative settings such as $\mathrm{FC}$ and $\mathrm{PjBL}$ after using a novel group learning environment, COGLE. It shows how NT and NAT were able to master content and learn to trust each other to come together as a team as they prepare for collaborative activities. They also completed the FC and PjBL activity that followed successfully. Staff can also benefit from the use of COGLE as it frees them from having to teach and instead they can focus on guiding students and this changes their role in the teaching process. COGLE prepares students before they set foot on the collaborative tasks that require team working, collaboration skills and mastery of technical knowledge, some of the most important pillars in engineering education. These initial results suggest that the learning gain results are generalisable to the population as shown by the rejection of the null hypotheses in both cases. The two cases show the transferability of the intervention design for mixed groups of NT and NAT students and this is supported by the comments from students from both cases. Further studies involving larger cohort sizes and in different engineering disciplines can help to strengthen understanding of how trust and mastery develops as well as with the transferability of the results.

\section{ACKNOWLEDGMENT}

This work benefited from the Dean's fund for supporting research within the school. The authors are also grateful for the continued support for this project as we investigate further collaborative learning within engineering education with bigger cohort sizes in order to make these results more generalisable. Authors also thank all three reviewers for their useful comments and suggestions.

\section{REFERENCES}

[1] Graham, R., 2010. UK approaches to engineering project-based learning. White Paper sponsored by the Bernard M. Gordon/MIT Engineering Leadership Program. http://web. mit. edu/gordonelp/ukpjblwhitepaper2010. pdf.

[2] Markes, I., 2006. A review of literature on employability skill needs in engineering. European Journal of Engineering Education, 31(6), pp.637-650.

[3] Jollands, M., Jolly, L. and Molyneaux, T., 2012. Project-based learning as a contributing factor to graduates' work readiness. European Journal of Engineering Education, 37(2), pp.143-154..

[4] Winberg, C., Bramhall, M., Greenfield, D., Johnson, P., Rowlett, P., Lewis, O., Waldock, J. and Wolff, K., 2018. Developing employability in engineering education: a systematic review of the literature. European Journal of Engineering Education, pp.1-16.

[5] Passow, H.J. and Passow, C.H., 2017. What competencies should undergraduate engineering programs emphasize? A systematic review. Journal of Engineering Education, 106(3), pp.475-526.Jollands, M., Jolly, L. and Molyneaux, T., 2012. Project-based learning as a contributing factor to graduates' work readiness. European Journal of Engineering Education, 37(2), pp.143-154..

[6] Karabulut - Ilgu, A., Jaramillo Cherrez, N. and Jahren, C.T., 2018. A systematic review of research on the flipped learning method in engineering education. British Journal of Educational Technology, 49(3), pp.398-411.

[7] Springer, L., Stanne, M.E. and Donovan, S.S., 1999. Effects of smallgroup learning on undergraduates in science, mathematics, engineering, and technology: A meta-analysis. Review of Educational 
Research, 69(1), pp.21-51.

[8] Akçayır, G. and Akçayır, M., 2018. The flipped classroom: A review of its advantages and challenges. Computers \& Education, 126, pp.334345 .

[9] Bishop, J.L. and Verleger, M.A., 2013, June. The flipped classroom: A survey of the research. In ASEE national conference proceedings, Atlanta, GA (Vol. 30, No. 9, pp. 1-18).

[10] Chen, J., Kolmos, A. and Du, X., 2020. Forms of implementation and challenges of PBL in engineering education: a review of literature. European Journal of Engineering Education, pp.1-26.

[11] Kokotsaki, D., Menzies, V. and Wiggins, A., 2016. Project-based learning: A review of the literature. Improving schools, 19(3), pp.267277.

[12] Taylor, M.J., 2005. Teaching students with autistic spectrum disorders in HE. Education+ Training

[13] Harmer, N. and Stokes, A., 2014. The Benefits and Challenges of Project-Based Learning-A Review of the Literature. Plymouth: PedRIO.

[14] Staggers, J., Garcia, S. and Nagelhout, E., 2008. Teamwork through team building: Face-to-face to online. Business Communication Quarterly, 71(4), pp.472-487.

[15] Fransen, J., Kirschner, P.A. and Erkens, G., 2011. Mediating team effectiveness in the context of collaborative learning: The importance of team and task awareness. Computers in Human Behavior, 27(3), pp.1103-1113.

[16] Colorosa, S.R. and Makela, C.J., 2014. Integrative Literature Review: Styles of Learning for Autism Spectrum Disorders and Human Resource Development: Informing Performance Management. International Journal of Business and Social Science, 5(13).

[17] Centers for Disease Control and Prevention. (2020). Autism Spectrum Disorder (ASD): Data and Statistics Retrieved from https://www.cdc.gov/ncbddd/autism/data/index.html.

[18] Centers for Disease Control and Prevention. (2020). Attention Deficit / Hyperactivity Disorder (ADHD): Data and Statistics Retrieved from https://www.cdc.gov/ncbddd/adhd/data.html.
[19] Who's studying in HE?: Personal characteristics. (2020). Higher Education Statistics Agency. Retrieved from https://www.hesa.ac.uk/data-and-analysis/students/whos-in-he

[20] Borrego, M., Karlin, J., McNair, L.D. and Beddoes, K., 2013. Team effectiveness theory from industrial and organizational psychology applied to engineering student project teams: A research review. Journal of Engineering Education, 102(4), pp.472-512.

[21] Crouch, C.H. and Mazur, E., 2001. Peer instruction: Ten years of experience and results. American Journal of physics, 69(9), pp.970$977 \mathrm{p}$

[22] Kennedy, G.E. and Cutts, Q.I., 2005. The association between students' use of an electronic voting system and their learning outcomes. Journal of Computer Assisted Learning, 21(4), pp.260-268.

[23] Bloom, B.S., 1968. Learning for Mastery. Instruction and Curriculum. Regional Education Laboratory for the Carolinas and Virginia, Topical Papers and Reprints, Number 1. Evaluation comment, 1(2), p.n2.

[24] Khan, S. and Slavitt, E., 2013. A bold new math class. Educational Leadership, 70(6), pp.28-31.

[25] Ebert, T.A., 2009. Facets of trust in relationships-A literature synthesis of highly ranked trust articles. Journal of Business Market Management, 3(1), pp.65-84.

[26] Mayer, R.C., Davis, J.H. and Schoorman, F.D., 1995. An integrative model of organizational trust. Academy of Management Review, 20(3), pp.709-734.

[27] McAllister, D.J., 1995. Affect-and cognition-based trust as foundations for interpersonal cooperation in organizations. Academy of Management journal, 38(1), pp.24-59.

[28] Aiken, K.D. and Boush, D.M., 2006. Trustmarks, objective-source ratings, and implied investments in advertising: investigating online trust and the context-specific nature of internet signals. Journal of the Academy of Marketing Science, 34(3), pp.308-323.

[29] Yang, Y., Tian, Y., Fang, J., Lu, H., Wei, K. and Yi, L., 2017. Trust and deception in children with autism spectrum disorders: A social learning perspective. Journal of Autism and Developmental Disorders, 47(3), pp.615-625.

[30] Stake, R.E., 1995. The art of case study research. Sage. 